\title{
Projeto e gestão de processos em pequenas empresas: o caso de uma pequena confeitaria de bairro
}

Bruno Blanco ${ }^{1}$

${ }^{1}$ Universidade Federal do Rio de Janeiro 


\section{PROJETO E GESTÃO DE PROCESSOS EM PEQUENAS EMPRESAS: O CASO DE UMA PEQUENA CONFEITARIA DE BAIRRO}

\section{Resumo:}

As pequenas empresas são bastante relevantes no cenário nacional, seja pela representatividade em quantidade ou pelo papel que exercem socialmente e economicamente. Porém, tradicionalmente, essas organizações enfrentam dificuldades que tornam a sua gestão complexa e desafiante. Sendo assim, como uma forma de contribuir para práticas melhores de gestão em pequenos negócios, este trabalho teve como objetivo conhecer e apresentar os impactos de projetar e gerenciar processos nessas empresas. Trata-se, portanto, de uma pesquisa qualitativa com método de pesquisa-ação aplicado em uma confeitaria de pequeno porte. Buscou-se entender como gerenciar processos diante das especificidades desse tipo de empresa e se essa abordagem pode trazer benefícios para essas organizações. Como resultados da pesquisa foram encontrados a melhoria no desempenho geral dos processos produtivos, além da identificação da influência de algumas dessas especificidades na implementação da gestão de processos, principalmente a escassez de recursos financeiros, humanos e de tempo.

Palavras-chave: Pequenas empresas. Gestão de processos. Gestão da produção. Pesquisaação. 


\section{Introdução}

As pequenas empresas são bastante relevantes para o nosso país, mas apesar disso, a grande maioria da literatura sobre organizações vem priorizando os grandes negócios. Para a área de gestão de processos, o cenário é semelhante: poucas são as discussões da abordagem de processos face às características específicas desse tipo de organização.

Sabe-se que as organizações de pequeno porte apresentam características próprias e diferentes das organizações maiores e que, por esse motivo, devem existir estudos voltados especificamente para este tipo de empresa. (TORRES; JULIEN, 2005 e WELSH; WHITE, 1981) Uma dessas características é a dificuldade na gestão. Em uma pesquisa realizada pela Vox Populi (2005), falhas gerenciais foram citadas por 55\% dos empresários como as maiores dificuldades na condução de empresas. Além disso, 78\% das empresas ativas consideraram as habilidades gerenciais como um dos fatores que podem contribuir para o sucesso do negócio.

Trabalhos acadêmicos também apresentam resultados sobre os fatores que influenciam o desempenho da pequena empresa. Uma pesquisa quantitativa, realizada por Grapeggia et al (2011) com mais de trezentos pequenos empresários de Santa Catarina, buscou apontar os fatores condicionantes de sucesso ou fracasso segundo os próprios empreendedores. Os empreendedores consideraram todos os fatores internos, relacionados à gestão da empresa, como mais importantes para o sucesso comparados aos aspectos externos.

Ou seja, adotar práticas gerenciais adequadas gera um impacto positivo sobre o desempenho de pequenas empresas, aumentando inclusive suas chances de sobrevivência. (MIZUMOTO et al, 2010, VOGEL; WOOD, 2012) Porém diversas são as práticas de gestão que podem contribuir para melhores resultados de performance. A abordagem de projetar e gerenciar processos é uma delas.

No entanto, como já foi dito, a gestão de processos não é muito difundida e implementada nos pequenos negócios. Há uma lacuna e uma demanda de materiais didáticos e projetos de pesquisa direcionados a esse tema. (RIBEIRO, 2008)

Segundo Chong (2007), essa escassez pode levar a uma falsa impressão de que os benefícios advindos da orientação por processos só são aplicáveis a grandes empresas. Além disso, essa falta de pesquisas limita a adoção dessa prática gerencial por pequenos

\section{Organizadores:}

Realizadores:

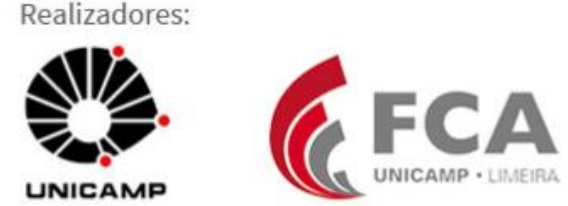

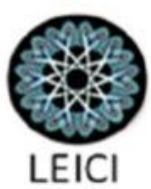


empresários, já que, sem conhecimento, eles ficam incapazes de avaliar o risco de implementá-la.

Apesar disso, há alguns estudos que discutem a gestão de processos em pequenos negócios. E, segundo os pesquisadores (McCormack, 2001 e Chong, 2007), os benefícios da gestão de processos também são aplicados aos pequenos negócios. Alguns deles são: melhor eficiência operacional, aumento da rentabilidade, melhorias nas relações com clientes, tempos de ciclo dos processos mais curtos, custos operacionais mais baixos e maior competitividade no mercado.

Dentro desse contexto, esta pesquisa ter por objetivo conhecer e apresentar os impactos da realização de tarefas de projeto e gestão de processos em pequenas empresas. De maneira mais detalhada, nesta pesquisa foi analisada a aplicação da abordagem de projeto e gestão de processos em uma pequena empresa, destacando a contribuição dessa abordagem para a melhoria dos processos produtivos dessa organização. Uma pequena confeitaria de bairro foi utilizada como caso para a estudo científico.

\section{Referencial Teórico}

O referencial teórico está dividido em dois momentos: as pequenas empresas e a gestão de processos dentro do universo dessas organizações.

\section{Pequenas empresas}

Do ponto de vista acadêmico, segundo Oliveira (2006), o estabelecimento de referências comuns, como a classificação por porte, são essenciais para a realização de estudos comparativos entre empresas. Dessa forma, reduz-se o espectro de análise para empresas com características mais próximas, gerando um universo de estudo mais homogêneo.

Assim sendo, para categorizar as empresas em micro, pequenas, médias e grande porte são utilizados diversos critérios, sendo os mais usados: faturamento e número de funcionários. O fato é que as micro e pequenas empresas (MPE) têm uma grande relevância no cenário brasileiro. Segundo o anuário do SEBRAE (2017), as MPE representam 99\% dos estabelecimentos e empregam 53,9\% da população brasileira. Além de serem a grande maioria, diversos autores da área concordam que esse grupo de organizações apresenta, em 
geral, características distintas das grandes empresas, ou seja, peculiaridades referentes ao seu grupo.

Sobre essa questão, para Torres e Julien (2005), existem dois caminhos distintos para orientar as discussões sobre especificidade das empresas de pequeno porte. $\mathrm{O}$ primeiro caminho, adotado pela maioria da comunidade acadêmica, é realizar pesquisas sob o paradigma das especificidades desse tipo de organização, o que eles chamam de "escola clássica". Outro caminho é assumir uma postura crítica diante dessas especificidades. (TORRES; JULIEN, 2005)

Dentro do que seria a "escola clássica" nomeada por Torres e Julien (2005), Welsh e White comentam, em um importante artigo da Havard Business Review em 1981, que as pequenas empresas apresentam uma condição especial relacionada com a pobreza de recursos que as diferencia das grandes empresas e, por isso, requerem abordagens de gestão diferenciadas. Ou seja, elas não podem ser consideradas grandes organizações em menor escala. (WELSH; WHITE, 1981)

Já Torres (2004), em busca de um elemento aglutinador para essas especificidades, faz uma relação das características definidas por Pierre-André Julien sobre as pequenas empresas com o termo "proximidade". Julien é reconhecido como um dos principais autores sobre o tema, o que justifica a escolha de Torres. As características citadas por Julien são: gestão centralizada; baixo nível de especialização dos funcionários; sistemas de informação externos e internos simples, informal e direto; estratégia intuitiva, implícita e de curto-prazo.

\section{Gestão de processos em pequenas empresas}

Sabe-se que a gestão dos processos pode trazer diversos benefícios para as organizações, mas para isso são necessárias algumas mudanças significativas, algumas vezes radicais, nas práticas gerenciais, na cultura empresarial e, em alguns casos, na estrutura organizacional. (DAVENPORT, 1994, HAMMER; CHAMPY, 1994 e PAIM et al, 2009)

No entanto, como já foi comentado, as pesquisas sobre gestão de processos analisam seus efeitos majoritariamente nas grandes empresas. A pesquisa de Chong (2007) está entre as poucas que fazem uma análise da gestão de processos dentro do ambiente específico de pequenas organizações. Segundo o autor, a escassez relativa de pesquisas sobre a implementação de BPM (Business Process Management) em pequenos negócios resultou na 
propagação generalizada de uma falsa impressão de que a otimização resultante da orientação por processos só são aplicáveis a grandes empresas. Porém, apesar de prevalecer essa suposição, é evidenciado em alguns estudos que as técnicas de otimização de processos podem ser igualmente eficazes quando aplicados aos pequenos negócios.

Outra pesquisa dentro do universo de pequenos negócios é de Golann (2006), que analisou as relações entre gestão de processos e a capacidade de resposta e orientação ao mercado em organizações de pequeno porte. $\mathrm{O}$ autor concluiu que a prática de gestão de processos teve um impacto geral positivo sobre a capacidade da empresa de assimilar informações do mercado e responder rapidamente a essas informações. Através dessa melhoria na orientação ao mercado, houve outras consequências positivas para as organizações analisadas, mais especificamente, a gestão de processos contribuiu para melhorar o desenvolvimento de produtos inovadores, a customização dos produtos e o suporte aos clientes.

Golann (2006) cita um caso da sua pesquisa em que a gestão de processos conseguiu diminuir radicalmente o que o empresário chamou de "viver apagando incêndio", característica bastante comum nos pequenos negócios. Segundo o empresário, a empresa era muito informal e sem procedimentos definidos. Por conta disso, os funcionários viviam "apagando incêndio" e mergulhando cada vez em mais problemas, ao ponto de entregar produtos que eles sabiam que tinham defeitos apenas para cumprir prazos. Com a melhoria na gestão de processos, a qualidade dos produtos feitos sob encomenda melhorou significativamente. A taxa de defeitos caiu de $13 \%$ para $0,5 \%$.

Mas a pesquisa de Golann (2006) também apresenta um importante impacto negativo da gestão de processos em pequenas empresas. Esse impacto foi citado por dois dos seis casos estudados: a perda de flexibilidade ou excesso de burocratização. Para um dos empresários, a formalização dos métodos de trabalho levou os funcionários a se sentirem sem liberdade de decisão. Além disso, a burocratização levou ao aumento excessivo no tempo de um processo.

Portanto, um desafio importante na gestão de processos é o seu potencial de criar sistemas inflexíveis que reduzem a agilidade. Uma solução para isso é incluir procedimentos e regras de decisão para agir diferente do modelo proposto, quando necessário. Dessa forma, busca-se satisfazer as demandas do cliente, contribuindo para responder mais rapidamente às 
mudanças no mercado. Em alguns casos, é importante dar certa autonomia ao funcionário para tomar decisões mais rápidas. (GOLANN, 2006)

Albuquerque (2012) também faz referência a essa relação entre formalização dos processos e flexibilidade. Segundo o autor, os modelos de processos são considerados formais e "mortos", enquanto as rotinas organizacionais são de natureza informal e "viva", sendo assim, os modelos seriam rígidos e inflexíveis por sua própria natureza. Acrescentando a esse raciocínio, Albuquerque (2012) cita Law (2009) que diz que toda tradução é também uma traição, fazendo uma analogia aos modelos de processos.

No entanto, Albuquerque (2012) concluiu que essa relação entre formalização e flexibilidade é mais complexa do que a relação de exclusão mútua unidimensional comumente assumida. Para o autor, ela é multidimensional e os projetos de BPM devem contrabalançar a formalização advinda da modelagem de processos com estratégias de gestão de mudanças, assegurando a manutenção da flexibilidade organizacional.

Essas conclusões devem ser melhores investigadas, entretanto, os autores apresentaram resultados importantes a respeito da gestão de processos em pequenas empresas e ressaltaram impactos negativos e positivos em algumas características específicas a essas organizações, como a flexibilidade e a informalidade.

Porém, o contrário também ocorre: essas especificidades impactam diretamente na implementação da gestão de processos. Foi o que analisou Chong (2007) em sua pesquisa, quando identificou os fatores inibidores na implementação do BPM em pequenas organizações. Após analisar algumas pesquisas na literatura somados aos resultados de sua própria pesquisa, Chong (2007) revela que os principais fatores inibidores são: ausência de mentalidade transversal entre áreas funcionais por parte dos gestores, falta de apoio da alta administração, falta de clareza no nível estratégico, falta de expertise em TI, conhecimento pobre sobre abordagens orientadas por processos, falta de recursos financeiros e falta de tempo.

Diante disso, é válido destacar que possa existir uma relação entre a adoção limitada da gestão de processos por parte das pequenas empresas e o fato dos pequenos empresários não estarem cientes dos benefícios dessa prática. Sem conhecimentos sobre os investimentos e 
os resultados do BPM dentro de seu universo, esses empresários não tem capacidade de avaliar o risco que envolve esse projeto. (CHONG, 2007)

\section{Metodologia da pesquisa}

Essa pesquisa é qualitativa com método de pesquisa-ação. Qualitativa não pela falta de quantificação de variáveis, mas por se aproximar dos conceitos dessa abordagem. Para Miguel et al (2010), a pesquisa qualitativa preocupa-se em obter informações sobre a perspectiva dos indivíduos e em interpretar o ambiente em que a problemática acontece, ou seja, o ambiente natural dos indivíduos é o ambiente da pesquisa.

Assim sendo, para Miguel et al (2010), os métodos de pesquisa mais apropriados para conduzir uma pesquisa qualitativa são o estudo de caso e a pesquisa-ação. O método dessa pesquisa é a pesquisa-ação, porque, "em contrate com o estudo de caso, o pesquisador tem um envolvimento grande com os indivíduos e a organização. Ele faz parte da equipe que realiza a mudança organizacional por meio da pesquisa”. (MIGUEL et al, 2010, p. 54)

Nesse contexto, e baseado nas fases de Thiollent (2009, p. 32) para a pesquisa-ação em organizações, esta pesquisa segue os seguintes passos: Levantamento bibliográfico; Diagnóstico do problema na organização; Planejamento da ação; Execução das ações; Avaliação das consequências da ação; Aprendizagem e conclusões.

Essa pesquisa-ação foi, então, realizada através de um projeto de consultoria. Ou seja, a empresa que participou da pesquisa vislumbrou no serviço de consultoria uma esperança em obter melhorias em seus processos produtivos como redução de custos, aumento na qualidade dos produtos, maior velocidade nos processos, entre outros. Sendo assim, alinhando os anseios do empresário e os objetivos desta pesquisa, chegou-se a um objetivo comum para o projeto: melhorar a gestão de processos produtivos em busca de atingir melhores resultados nos objetivos de desempenho (custo, qualidade, velocidade, confiabilidade e flexibilidade).

Portanto, optou-se por analisar somente os processos produtivos da empresa como forma de aprofundar mais nos detalhes dessas atividades vitais para as organizações. $\mathrm{O}$ que não significou atuar em uma única unidade funcional da empresa, na verdade, optou-se por analisar o processo principal de produção de forma transversal, pressupondo o entendimento de processos como aqueles que cruzam as unidades organizacionais.

\section{Organizadores:}

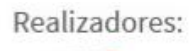

Realizadores: 
Definido o objetivo, um cronograma foi desenvolvido baseado no roteiro de tarefas definidas por Paim et al (2009). O caso escolhido para ser estudado é de uma confeitaria situada no bairro de Botafogo, na cidade do Rio de Janeiro, há trezes anos. Essa empresa oferece serviços de venda e entrega de diversos tipos de tortas, doces e salgados, além de vender produtos para consumo imediato em um espaço dedicado a uma lanchonete. A ideia de criar essa confeitaria em Botafogo veio do sucesso de outra confeitaria da família em outro bairro da cidade.

$\mathrm{Na}$ produção, as reclamações do empresário eram grandes: atrasos nas entregas, erros no pedido, falta de organização, desperdício, entre outros. Problemas que acarretavam em perda de lucro e insatisfações dos clientes.

\section{Apresentação de resultados: gestão de processos na prática}

A intervenção na confeitaria aconteceu em três fases. A primeira foi o projeto de processos, onde foram realizadas tarefas como análises do ambiente da empresa, modelagem dos processos (na situação atual e futura) e priorização dos problemas e das soluções (utilizando a ferramenta Árvore de Realidade Atual). A segunda fase constituiu na execução das soluções, com algumas correções e adaptações ao longo da intervenção.

$\mathrm{Na}$ fase final, foi feita uma avaliação dos resultados, consolidando a aprendizagem sobre os processos. O registro do desempenho dos processos ao longo do tempo foi essencial nessa fase. Esse registro foi realizado com a ferramenta Matriz Importância-Desempenho de Slack (1993), utilizando escalas de importância e desempenho e alguns critérios de avaliação, são eles: custo (0), qualidade do produto (1), qualidade do processo (2), velocidade do processo (3), velocidade de entrega (4), confiabilidade de entrega (5), flexibilidade de projeto (6), flexibilidade de variedade (7), flexibilidade de volume (8) e flexibilidade de entrega (9).

A Matriz Importância-Desempenho avalia, como o nome já antecipa, a importância e o desempenho em fatores competitivos escolhidos com base nos cinco objetivos da produção custo, qualidade, velocidade, confiabilidade e flexibilidade. Para fazer essa avaliação, Slack (1993) desenvolveu uma escala de nove pontos tanto para importância quanto para o desempenho. Vale ressaltar que a avaliação de importância é feita com base na visão dos clientes e a avaliação de desempenho comparando com os concorrentes. 
Para avaliar a importância e o desempenho desses critérios, foram feitas entrevistas com o principal gestor da confeitaria nos dois momentos de avaliação: no início do projeto de processos e após as implementação das mudanças. Após as entrevistas, os critérios foram posicionados dentro da matriz. A figura 1 mostra a Matriz Importância-Desempenho anterior às mudanças.

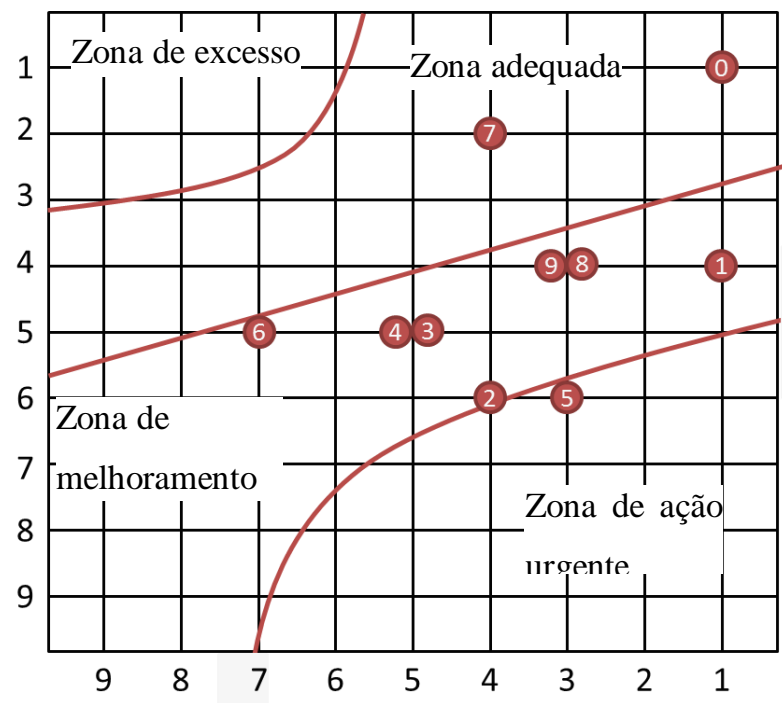

Figura 1 - Matriz Importância-Desempenho da confeitaria antes do projeto.

Apenas dois critérios se encontravam na zona adequada: flexibilidade de variedade (critério 7) e custo (critério 0). O critério com pior resultado e que se encontrava na zona de ação urgente era a confiabilidade de entrega (critério 5). Todos os outros se posicionavam na zona de melhoramento, precisando de melhorias em seu desempenho.

Após as melhorias na gestão dos processos produtivos, em alguns critérios não houve melhora no desempenho, mas em outros o desempenho cresceu, como foi o caso da qualidade do processo (critério 2), da velocidade do processo (critério 3), da confiabilidade da entrega (critério 5) e da flexibilidade de volume (critério 8). Sendo assim, apenas quatro critérios ficaram na zona de melhoramento, todos os outros cinco se posicionaram na zona adequada. Esse crescimento no desempenho é possível visualizar na Matriz apresentada na figura 2. 


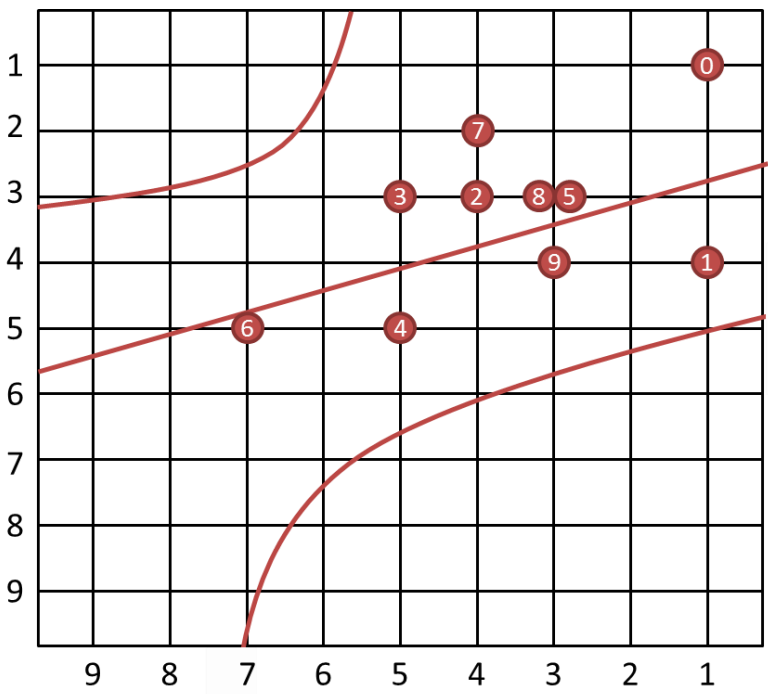

Figura 2 - Matriz Importância-Desempenho da confeitaria após o projeto.

Para tentar quantificar essa melhora no desempenho da área de produção e servir como um complemento de análise, o autor desenvolveu uma ferramenta que calculou uma pontuação geral do desempenho da produção. Para isso, definiu pesos para a importância do critério e quantidade de pontos para o desempenho. Os critérios com importância 1, dentro da escala de nove pontos, receberam o peso 9 no cálculo e aqueles com importância 9 receberam o peso 1. Para o desempenho foi utilizada a mesma lógica.

Através dessa ferramenta foi possível identificar um crescimento no desempenho geral nos processos produtivos da confeitaria de 384 pontos para 440 pontos, demonstrando um avanço $14,58 \%$ com o uso da abordagem de gestão de processos. Uma comparação com outras empresas enriqueceria as análises nesse caso.

\section{Conclusões}

Esta pesquisa buscou encontrar respostas para duas questões principais: como projetar e gerenciar processos diante das especificidades das pequenas empresas? E se a melhoria na gestão dos processos de negócio pode trazer benefícios para os processos produtivos desse tipo de organização? Para a primeira questão, o conjunto de tarefas de gestão de processos definidas por Paim et al (2009), voltada para qualquer porte de organização, se mostrou suficientemente adequado a realidade das pequenas empresas. O que não significa que 
gerenciar processos em um pequeno negócio seja semelhante à fazê-lo em grandes corporações.

As pequenas organizações possuem especificidades que muitas vezes exigem um método de gestão diferenciado. Um exemplo disso foi a realização da tarefa de modelagem dos processos na situação futura. Houve uma maior preocupação em não prejudicar a capacidade de flexibilidade, característica marcante das empresas de pequeno porte. Assim, ações diferentes na modelagem tiveram que ser tomadas.

Outro aspecto das especificidades das pequenas empresas é a "condição de pequenez" citada por Anderson e Ullah (2014). Para eles algumas características do pequeno negócio e do pequeno empresário prejudicam o crescimento desse tipo de organização, principalmente a relutância do empreendedor em querer crescer. Sendo assim, cada pequena empresa tem seus objetivos e a gestão de processos deve se adequar a isso.

Outra peculiaridade desse tipo de organização a qual houve necessidade de se adequar foi a escassez de recursos, tanto financeiro, humano ou de tempo. O desenvolvimento do projeto e a implementação das soluções tiveram que se adaptar a essa condição de escassez. $\mathrm{Ou}$ seja, foram sugeridas soluções baratas e de fácil implementação e utilização pelos funcionários.

O apoio do empresário e da gerência se mostrou outro fator decisivo para as transformações implementadas, principalmente na resistência por parte dos funcionários. As características da pequena empresa de gestão bastante centralizada, baixo nível hierárquico, informalidade e proximidade com seus funcionários tornam esse fator ainda mais importante.

Influenciou também na resistência, a abordagem para promover as mudanças. A abordagem mais radical escolhida gerou mais resistência por parte dos colaboradores, apesar de não ser possível concluir uma relação direta entre um e outro. O que foi percebido é que houve melhoria na performance geral dos processos produtivos, o que serve como resposta para a segundo questionamento dessa pesquisa.

Porém, na avaliação do resultado da intervenção, algumas dificuldades foram enfrentadas na utilização da Matriz Importância-Desempenho de Slack (1993). Ao avaliar a importância, entender o quão relevante eram alguns fatores competitivos para o cliente não foi algo trivial, resultando em percepções bastante subjetivas sobre essa importância. Essa 
subjetividade também esteve presente na avaliação do desempenho, nesse caso, faltaram informações mais concretas sobre a performance dos concorrentes, dificultando a comparação entre eles e a organização analisada.

Além disso, outra especificidade influenciou na não utilização de métricas complementares à Matriz Importância-Desempenho: a prática de não retenção das informações sobre o negócio. Ou seja, a falta de informações claras sobre a performance das empresas impossibilitou a utilização de outras métricas que complementariam a avaliação do resultado das intervenções. Informações como rentabilidade, faturamento, aumento no número de funcionários e outras não puderam ser utilizadas.

Logo, é importante ressaltar que esse estudo foi feito em apenas uma organização em circunstâncias bem específicas e com percepções subjetivas por parte do empresário. $\mathrm{O}$ resultado seria diferente para cada nova empresa que recebesse a consultoria, o que impossibilita a conclusão de que implementar melhorias na gestão de processos trará sempre benefícios para o processo produtivo das organizações de pequeno porte.

Enfim, realizar melhorias na gestão de processos pode vir trazer benefícios para o processo de produção de uma pequena empresa. Apesar disso, o projeto, incluindo as soluções propostas por ele, e a gestão diária desses processos devem se adequar as características desse tipo de organização.

Sendo assim, esta pesquisa apresenta alguns resultados relevantes, mas também algumas limitações que merecem destaque. Uma delas está em ser apenas um caso e em suas características bem específicas. As organizações de pequeno porte apresentam a heterogeinidade como uma das suas peculiaridades, o que dificulta estudos e pesquisas dentro desse universo. Para esta pesquisa, a própria escolha da metodologia da pesquisa e essa heterogeinidade inviabilizam a generalização dos resultados para todo e qualquer tipo de organização de pequeno porte.

Outra limitação está na métrica utilizada para a avaliação dos resultados na intervenção e, portanto, utilizada para descobrir se a gestão de processos trouxe ou não benefícios para a organização que fez parte da pesquisa. Como já foi comentado, a utilização de somente uma métrica que é altamente subjetiva, onde o empresário era quem determinava 
a importância e o desempenho obtido em cada critério, torna mais frágil a conclusão a cerca dos benefícios encontrados.

Isso nos leva a crer, que trabalhos futuros que utilizem métricas mais objetivas e com menos interferência seriam importantes. Uma sugestão, portanto, seria de uma pesquisa quantitativa que abrangesse um número maior de pequenas empresas em busca de fatores inibidores da implementação da gestão de processos em pequenas empresas. Mais uma sugestão válida seria outra pesquisa quantitativa que correlacionasse a gestão de processos com métricas de desempenho de pequenos negócios.

Enfim, novas pesquisas abordando a gestão de processos em organizações de pequeno porte são essenciais para que dissemine esse conhecimento e permita aos pequenos empresários conhecer os benefícios, as desvantagens, as dificuldades e os riscos de adotar essa prática gerencial.

\section{Referências}

ANDERSON, A. R.; ULLAH, F. The condition of smallness: how what it means to be small deters firms from getting bigger. Management Decision, v. 52, n. 2, p. 326-349, 2014

ALBUQUERQUE, J. DE. Flexibilidade e modelagem de processos de negócio: uma relação multidimensional. RAE-Revista de Administração de Empresas, v. 52, n. 3, p. 313329,2012

CHONG, S. Business process management for SMEs: an exploratory study of implementation factors for the Australian wine industry. Journal of Information Systems and Small Business, v. 1, n. 1, p. 41-58, 2007.

DAVENPORT, T. H. Reengenharia de Processos. Rio de Janeiro: Ed. Campus, 1994.

GOLANN, B. Achieving Growth and Responsiveness: Process Management and Market Orientation in Small Firms. Journal of Small Business Management, v. 44, n. 3, p. 369-385, 2006.

GRAPEGGIA, M. et al. Fatores condicionantes de sucesso e/ou mortalidade de micro e pequenas empresas em Santa Catarina. Produção, v. 21, n. 3, p. 444-455, set. 2011. 
HAMMER, M.; CHAMPY, J. Reengenharia: repensando a empresa em função dos clientes, da concorrência e das grandes mudanças da gerência. Rio de Janeiro: Ed. Campus, 1994.

MCCORMACK, K. Business process orientation: do you have it? Quality Progress, v. 34, n. 1, p. $51-60,2001$.

MIGUEL, P. A. C. et al. Metodologia de Pesquisa em Engenharia de Produção e GEstão de Operações. Rio de Janeiro: Elsevier, 2010.

MIZUMOTO, F. M. et al. O impacto de capital humano, capital social e práticas gerenciais na sobrevivência de empresas nascentes: um estudo com dados de pequenas empresas no Estado de São Paulo. Revista de Administração da USP, v. 45, n. 4, p. 343-355, 2010 .

OLIVEIRA, O. Pequena empresa no Brasil: um estudo de suas características e perspectivas. Integração, v. 12, no 44, p. 5-15, 2006.

PAIM, R.; CARDOSO, V.; CAULLIRAUX, H.; CLEMENTE, R. Gestão de processos: pensar, agir e aprender. Porto Alegre: Bookman, 2009. 328 p.

RIBEIRO, A. B. Fatores que impactam o desempenho de pequenas empresas. 2008. 379 p. Tese (Doutorado em Engenharia de Produção). Universidade Federal do Rio de Janeiro. Rio de Janeiro.

SEBRAE; DIEESE. Anuário do Trabalho na Micro e Pequena Empresa - 2015. São Paulo, 2017. Disponível em: <www.biblioteca.sebrae.com.br>.

SLACK, Nigel. Vantagem competittiva em manufatura: atingindo competitividade nas operações industriais. São Paulo: Atlas, 1993.

THIOLLENT, Michel. Pesquisa-ação nas organizações. $2^{\circ}$ edição. São Paulo: Atlas, 2009.

TORRES, O. The SME concept of Pierre-André Julien: an analysis in terms of proximity.

Piccola Impresa/Small Business, $n^{\circ}$ 2, p. 1-12, 2004.

TORRES, O.; JULIEN, P.-A. Specificity and Denaturing of Small Business. International Small Business Journal, v. 23, n. 4, p. 355-377, 2005.

VOGEL, J.; WOOD, T. Práticas gerenciais de pequenas empresas industriais do Estado de São Paulo: um estudo exploratório. Revista de Empreendedorismos e Gestão de Pequenas Empresas, v. 1, n. 2, p. 117-140, 2012. 
VOX POPULI. Fatores condicionantes e taxa de mortalidade das MPE. Rio de Janeiro, 2005. Disponível em: <www.biblioteca.sebrae.com.br>.

WELSH, J.; WHITE, J. A small business is not a little big business. Harvard business review, n. 81411, 1981. 